\title{
Plasma Levels and Tissue Expression of Selected Cytokines, Metalloproteinases and Tissue Inhibitors in Patients With Cervical Cancer
}

\author{
IWONA SIDORKIEWICZ ${ }^{1}$, BARBARA PISKÓR ${ }^{2}$, EMILIA DĄBROWSKA ${ }^{2}$, \\ KATARZYNA GUZIŃSKA-USTYMOWICZ ${ }^{3}$, ANNA PRYCZYNICZ ${ }^{3}$, \\ MONIKA ZBUCKA-KRĘTOWSKA ${ }^{4}$ and SŁAWOMIR ŁAWICKI ${ }^{5}$ \\ ${ }^{1}$ Clinical Research Centre, Medical University of Bialystok, Bialystok, Poland; \\ ${ }^{2}$ Department of Aesthetic Medicine, Medical University of Bialystok, Bialystok, Poland; \\ ${ }^{3}$ Department of General Pathomorphology, Medical University of Bialystok, Bialystok, Poland; \\ ${ }^{4}$ Department of Reproduction and Gynecological Endocrinology, Bialystok, Poland; \\ ${ }^{5}$ Department of Population Medicine and Civilization Diseases Prevention, \\ Medical University of Bialystok, Bialystok, Poland
}

\begin{abstract}
Background: Cytokines, metalloproteinases (MMPs) and their tissue inhibitors (TIMPs) take part in many processes involved in tumor progression and invasion such as degradation of the extracellular matrix, influence on immune cells associated with tumor tissue, and angiogenesis. Thus, the aim of this study was to compare the concentration of plasma levels and tissue expression of macrophage colony-stimulating factor (M-CSF), vascular endothelial growth factor (VEGF), matrix metalloproteinases (MMP)-2 and MMP9, and their tissue inhibitors TIMP1 and TIMP2 in patients with cervical cancer, patients with high-grade cervical intraepithelial dysplasia (CIN3) and patients with ectropion. Patients and Methods: Concentration and expression of all tested parameters was measured in serum with enzyme-linked immunosorbent assay (ELISA) and in tissue with immunohistochemistry method. Results: The epithelial expression of M-CSF and TIMP1 in cancer tissue was much stronger as compared to that in ectropion and CIN3. In the case of MMP2, lack of or weak expression in epithelial cells was observed in all tested groups. Our studies showed statistical differences of tested parameters in tissue expression and in plasma concentrations in patients with
\end{abstract}

Correspondence to: Iwona Sidorkiewicz (ORCID ID: 0000-00030254-3095), Clinical Research Centre, Medical University of Bialystok, Sklodowskiej-Curie 24a, 15-276 Bialystok, Poland. Email: iwona.sidorkiewicz@umb.edu.pl

Key Words: Tumor marker, cervical cancer, matrix metalloproteinases, tissue inhibitors of matrix metalloproteinases, macrophage colony-stimulating factor, vascular endothelial growth factor. cervical cancer, patients with CIN3 and patients with ectropion. Moreover, data revealed positive correlation between plasma level and cervical cancer cell expression of VEGF. Conclusion: Our findings indicate a potential role of all the proteins tested here in cervical cancer diagnosis, especially VEGF. However, further studies will show whether they play a role in the progression of cancerous changes in epithelial tissue of the cervix.

Cervical cancer remains one of the most common malignant tumors. Epidemiological data show that it has become a significant health problem, particularly in women in developing countries. The development of cervical cancer is well studied and involves dysplasia, its progression to a precancerous stage and invasion through the epithelium (1). Treatment of cervical cancer depends on the clinical stage and may include surgery, chemotherapy and radiation therapy, alone or followed by surgery. Organized screening programs for cervical cancer using annual cytology appear to be effective and, thus have reduced the incidence of cervical cancer (2). However, the main problem in cervical cytology screening is its low sensitivity and reproducibility, leading to variable accuracy (3). Therefore, new, less invasive diagnostic biomarkers improving the detection of cervical cancer and clinical performance are needed. Proteinbased biomarkers might be effective in early detection, especially at a curable stage, and helpful in the prediction of treatment response (4).

Tumor invasion and metastasis, which involve the disruption of the basement membrane and extracellular matrix (ECM) remodeling, are key characteristics in the progression of cancer. Although many proteases have been associated with cancer progression, a specific group of more 
than 20 enzymes called matrix metalloproteinases (MMPs) may play a key role. They are synthesized and secreted by cells in an inactive form (5). MMP2 and MMP9, which belong to gelatinase subfamily, share proteolytic activity against other extracellular matrix molecules (6). MMPs also cooperate in the cell migration process by leading to revealing new binding sites, cleaving cell-matrix receptors, and releasing ECM-bound chemoattractants (7). Several studies have connected MMP2 and MMP9 to tumor angiogenesis and growth (8-10). The function of MMPs in vivo is determined by the local balance between them and tissue inhibitors of metalloproteinases (TIMPs) that can form complexes with enzymes (11). There are four homologous members of the TIMP family. Both TIMP1 and -3 can form complexes with proMMP9 while TIMP2, -3 and -4 are capable of interaction with pro-MMP-22 (12). The imbalance between the MMPs and TIMPs activity may trigger cancer cell migration $(5,13)$ TIMP1 and TIMP2 levels correlate with a poor prognosis in many types of $(12,14-17)$.

Macrophage colony-stimulating factor (M-CSF) was identified as a hematopoietic growth factor that controls the proliferation, survival, and differentiation of macrophages. In inflammation, M-CSF stimulates macrophages to secrete cytokines and proteases (18). Increased expression of M-CSF and its receptor (M-CSF-R) is correlated with tumor progression and poor survival in breast, ovarian and prostate cancer (19-24). M-CSF has mainly been studied in breast carcinomas, where its expression is well described $(25,26)$.

Tumor progression is accompanied by an angiogenic switch as a result of protein released by the tumor and cells in the microenvironment. In this process, the balance between proand anti-angiogenic factors tilts towards proangiogenic factors such as VEGF, which can increase vascular permeability (2729). However, the exact role of these proteins with pleiotropic function needs a more detailed understanding. While proteases such as MMP9 may stimulate the production of angiogenic factors they have been also identified to suppress the angiogenic effects of VEGF (30).

Thus, this study aimed to compare the concentration of plasma levels and tissue expression of M-CSF, VEGF, MMP2, MMP9, TIMP1 and TIMP2 in patients with cervical cancer (CC) with high grade cervical intraepithelial dysplasia (CIN3) and patients with ectropion.

\section{Patients and Methods}

Study participants. Table I shows the tested groups. The study comprised 60 patients with invasive primary carcinoma of the uterine cervix (51 cases with squamous cell carcinoma and nine cases with adenocarcinoma of the cervix), 20 patients with highgrade cervical intraepithelial dysplasia (CIN3) and 20 patients with ectropion who were referred to the Department of Gynecology, Bialystok Medical University Teaching Hospital, Poland. The clinical stage and histological classification were determined
Table I. Characteristic of examined groups: Cervical cancer, cervical intraepithelial neoplasia grade 3 (CIN3) and ectropion.
Study group
Cervical ectropion $(n=20)$
Median age (range), years
CIN3 $(n=20)$
Median age (range), years
Cervical cancer $(\mathrm{n}=60)$
Median age (range), years
Squamous cell carcinoma, $n$
Adenocarcinoma, $\mathrm{n}$
$46(23-58)$
$42(22-61)$
$45(25-61)$
51
9

following the International Federation of Gynecology and Obstetrics (FIGO) criteria in all cases (31). Written consent including participants' statements regarding their medical history and lifestyle habits were obtained from all as previously stated (32). None of the patients had received chemo- or radiotherapy before sample collection. Pretreatment staging procedures included physical and blood examinations and ultrasound scanning, which also confirmed no inflammation. All samples were taken prior to any treatment. The study was performed according to the Strengthening the Reporting of Observational Studies in Epidemiology (STROBE) guidelines and approved by the local Ethics Committee (R-I-002/239/2014).

Plasma collection and storage. Venous blood samples were collected from each patient into a heparin sodium tube, centrifuged $2,000 \times g$ for $20 \mathrm{~min}$ to obtain plasma samples, and stored at $-85^{\circ} \mathrm{C}$ until assayed.

Measurement of M-CSF, VEGF, MMP2, MMP9, TIMP1 and TIMP2. The tested parameters (M-CSF, VEGF, MMP2, MMP9, TIMP1 and TIMP2) were measured with enzyme-linked immunosorbent assay (ELISA) (Quantikine Human Immunoassay; R\&D Systems, Abingdon, UK), according to the manufacturer's protocols, and duplicate samples were assessed for standard and samples. This assay employs the quantitative sandwich enzyme immunoassay technique. The values of intra- and inter-assay CVs were enclosed in the reagent kits. The assay does not exhibit cross-reactivity or interference with numerous human MMPs, TIMPs, cytokines and other growth factors.

Immunohistochemistry. The immunohistochemistry was carried out for three groups of patients' tissue: 31 cases with CC, 17 cases with CIN3 and five cases with ectropion. Formalin-fixed and paraffinembedded tissue specimens cut on a microtome into $4 \mu \mathrm{m}$ sections were deparaffinized in xylenes and hydrated in alcohols, as previously (32). To retrieve antigens sections were heated in a water-bath in EDTA (pH 9; M-CSF, VEGF and TIMP1 antigens) buffer and citrate buffer (pH 8; MMP2 and TIMP2 antigens) at $99.5^{\circ} \mathrm{C}$ for $20 \mathrm{~min}$. For MMP9 antibody the step of antigen retrieval was not required. Endogenous peroxidase was blocked in $3 \% \mathrm{H}_{2} \mathrm{O}_{2}$ for 5 min. Next, they were incubated with anti-human antibodies: rabbit polyclonal antibody against M-CSF (clone ab9693, dilution 1:100; Abcam) for $60 \mathrm{~min}$; mouse monoclonal antibodies against: VEGF (clone \#26503, dilution 1:100; R\&D Systems) for $60 \mathrm{~min}$; mouse monoclonal antibody to MMP2 (clone 17B11, overnight dilution 1:60; Leica Biosystems, Newcastle upon Tyne, UK); MMP9 (clone 15W2, dilution 1:80; Leica) for $60 \mathrm{~min}$; mouse monoclonal antibody to 
Table II. Plasma levels of tested parameters in patients with cervical cancer (CC), Cervical intraepithelial neoplasia grade 3 (CIN3) and cervical ectropion.

\begin{tabular}{lcccccc}
\hline Group & M-CSF $(\mathrm{pg} / \mathrm{ml})$ & VEGF $(\mathrm{pg} / \mathrm{ml})^{\mathrm{a}}$ & MMP2 $(\mathrm{ng} / \mathrm{ml})$ & MMP9 $(\mathrm{ng} / \mathrm{ml})^{\mathrm{b}, \mathrm{c}, \mathrm{d}}$ & ${\text { TIMP1 }(\mathrm{ng} / \mathrm{ml})^{\mathrm{b}}}^{\text {TIMP2 }(\mathrm{ng} / \mathrm{ml})^{\mathrm{b}, \mathrm{c}, \mathrm{d}}}$ \\
\hline Cervical ectropion & & & & & & \\
Median (range) & $477.6(144.8-776.6)$ & $124.1(48.9-613.3)$ & $208(144.5-309.0)$ & $69.3(42.2-480.0)$ & $45.5(20.1-199.2)$ & $88.2(64.0-136.1)$ \\
Mean \pm SD & $525.9 \pm 357.3$ & $147.2 \pm 123.9$ & $213 \pm 42.9$ & $111.5 \pm 99.7$ & $62.8 \pm 43.7$ & $89.5 \pm 16.4$ \\
CIN3 & & & & & \\
Median (range) & $400.1(220.6-986.2)$ & $111.5(27.1-426.9)$ & $194.8(119.5-288.6)$ & $276.4(16.0-515.6)$ & $67.6(16.0-153.1)$ & $70.2(51.5-91.3)$ \\
Mean \pm SD & $456.3 \pm 204$ & $140.9 \pm 102.9$ & $195.9 \pm 48.8$ & $276.6 \pm 170.6$ & $69.5 \pm 42$ & $71.6 \pm 12.3$ \\
CC & & & & & \\
Median (range) & $476.2(95.2-1696.7)$ & $136.9(11.8-615.5)$ & $206.8(124.8-379.0)$ & $339.6(49.5-1099.4)$ & $75.1(7.2-264.3)$ & $75.6(26.9-125.5)$ \\
Mean \pm SD & $551.1 \pm 359.4$ & $191.8 \pm 154.8$ & $219.9 \pm 58.09$ & $373.7 \pm 225.5$ & $87.6 \pm 62.4$ & $74.3 \pm 20.3$ \\
\hline
\end{tabular}

M-CSF: Macrophage colony-stimulating factor; MMP2/9: matrix metalloproteinase 2/9; TIMP1/2: tissue inhibitor of matrix metalloproteinase 1; VEGF: vascular endothelial growth factor. Significantly different: ${ }^{\mathrm{a} C C} v s$. CIN3: $p<0.01$; ${ }^{\mathrm{b} C C} v s$. ectropion: $p<0.001$; ${ }^{\mathrm{c}} \mathrm{CIN} 3 \mathrm{vs}$. ectropion: $p<0.01$; ${ }^{\mathrm{d} C C}$ vs. CIN3 vs. ectropion: $p<0.01$.

TIMP1 (clone 6F6a, dilution 1:750; Leica) for $15 \mathrm{~min}$; and TIMP2 (clone 46E5, dilution 1:20; Leica) for $60 \mathrm{~min}$. The reaction was visualized with a detection kit NovoLink Polymer (Novocastra, Poland) and 3,3'-diaminobenzidine chromogen (Novocastra, Poland). Hematoxylin was used to counterstain nuclei. Next slides were dehydrated in alcohol, rinsed in xylene and closed in DPX medium (Sigma Aldrich, Poole, UK). Positive and negative controls were also performed. Stained preparations were observed under a light microscope. The positive reaction of the investigated proteins was observed in the cell cytoplasm (magnification $\times 200$ ). Expression was evaluated using an immunoreactive score that represented the percentage of positive cells $(0$, none $1,<25 \% ; 2,25-50 \%$; and 3,50 $100 \%$; ) and the staining intensity ( 0 , no staining; 1 , light, yellow staining; 2 , moderate yellow staining; and 3, strong, brown staining). The reported score for each patient was the average of the scores in five areas of the slide. The total score ranged from 1 to 3 and protein expression was considered as none, 0 ; weak, score 1 ; moderate, score 2 ; and strong, score 3 .

Statistical analysis. Statistical analysis was performed by IBM SPSS Statistics for Windows 20.0 (IBM Corp., Armonk, NY, USA). The Shapiro-Wilk test for preliminary assessment revealed that the cytokine, metalloproteinases and their inhibitor levels did not follow a normal distribution. Consequently, statistical analysis between the examined groups of patients was performed using the Kruskal-Wallis and multivariate analysis of various data by the post-hoc DwassSteele-Crichlow-Flinger test. Pearson's chi-squared test and post-hoc test for two proportions including Bonferroni correction for multiple comparisons were used to perform analyses between the expression of all tested parameters in endothelial cells in tested groups. Comparative analyses of expression in epithelial cells and stromal cells were performed by using the Wilcoxon matched-pairs test. Statistically significant differences were defined as comparisons resulting in $p<0.05$.

\section{Results}

Plasma levels of proteins in patients with cervical ectropion, CIN3 and CC. The median value for VEGF in patients with CC $(136.9 \mathrm{pg} / \mathrm{ml})$ was significantly higher compared with that for the CIN3 group (111.5 pg/ml; $p<0.05)$. The median value for MMP9 in patients with CC (339.6 ng/ml) was significantly higher compared with that for the ectropion group (69.3 ng/ml; $p<0.001)$ (Table II).

Additionally, the median value for TIMP2 in the $\mathrm{CC}$ group $(75.6 \mathrm{ng} / \mathrm{ml})$ was significantly lower compared with the ectropion group $(88.2 \mathrm{ng} / \mathrm{ml})(p<0.01)$. Moreover, the median MMP9 value in the CIN3 group $(276.4 \mathrm{ng} / \mathrm{ml})$ was significantly higher compared to the median value in patients with ectropion $(p<0.01)$. The median TIMP2 level in the same group $(70.2$ $\mathrm{ng} / \mathrm{ml})$ was significantly lower than that in ectropion $(p<0.01)$.

Furthermore, higher MMP9 and lower TIMP2 plasma levels were observed in CC compared to CIN and in CIN3 compared to ectropion $(p<0.01)$.

Immunohistochemical expression of M-CSF, VEGF, MMP2, MMP9, TIMP1 and TIMP2 in epithelial cells in patients with cervical ectropion, CIN3 and CC. The expression of all tested proteins was observed in the cytoplasm of normal, dysplastic and tumor cells. M-CSF, MMP2 and TIMP1 epithelial expression was dependent on the type of cervical lesion $(p<0.01, p<0.05, p<0.05$, respectively, Table III). Strongest M-CSF and TIMP1 expression was observed in $\mathrm{CC}$, whereas MMP2 expression was rather weak or moderate but stronger in CC than in CIN3 and stronger in CIN3 than in ectropion. In the case of other parameters, no association was found $(p>0.05)$.

In the ectropion group, lack of or slightly marked expression of M-CSF was detected. Positive reaction for M-CSF was observed only in epithelial cells of patients with CC. Lack of or weak expression of MMP2 protein was observed in all tested groups. In patients with CC and CIN3, expression of TIMP1 was detected in all cases. Expression of TIMP1 was mainly moderate or strong, and was stronger in patients with $\mathrm{CC}$ in comparison to those with CIN3 or ectropion $(p<0.05)$. 
Table III. Comparison of the immunohistochemical expression of tested parameters in epithelial cells for all examined groups. Only statistically significant data are shown using Pearson's chi-squared test and post-hoc test for two proportions (including Bonferroni correction for multiple comparisons).

\begin{tabular}{|c|c|c|c|c|c|c|}
\hline & \multirow[b]{2}{*}{ Score } & \multirow[b]{2}{*}{ Ectropion, $\mathrm{n}(\%)$} & \multirow[b]{2}{*}{ CIN3, n (\%) } & \multirow[b]{2}{*}{$\mathrm{CC}, \mathrm{n}(\%)$} & \multicolumn{2}{|c|}{$p$-Value } \\
\hline & & & & & Pearson's & Post-hoc \\
\hline \multirow[t]{4}{*}{ M-CSF } & 0 & $3(30.0)$ & $5(27.8)$ & $0(0.0)$ & $<0.01$ & $\mathrm{a}, \mathrm{b}$ \\
\hline & 1 & $6(60.0)$ & $4(22.2)$ & $9(29.0)$ & & \\
\hline & 2 & $0(0.0)$ & $4(22.2)$ & $8(25.8)$ & & \\
\hline & 3 & $1(10.0)$ & $5(27.8)$ & $14(45.2)$ & & \\
\hline \multirow[t]{4}{*}{ MMP2 } & 0 & $2(20.0)$ & $5(27.8)$ & $10(32.3)$ & $<0.05$ & \\
\hline & 1 & $4(40.0)$ & $13(72.2)$ & $17(54.8)$ & & \\
\hline & 2 & $4(40.0)$ & $0(0.0)$ & $2(6.5)$ & & $\mathrm{b}, \mathrm{c}$ \\
\hline & 3 & $0(0.0)$ & $0(0.0)$ & $2(6.5)$ & & \\
\hline \multirow[t]{4}{*}{ TIMP1 } & 0 & $1(10.0)$ & $0(0.0)$ & $0(0.0)$ & $<0.05$ & \\
\hline & 1 & $0(0.0)$ & $0(0.0)$ & $6(19.4)$ & & \\
\hline & 2 & $2(20.0)$ & $5(29.4)$ & $12(38.7)$ & & \\
\hline & 3 & $7(70.0)$ & $12(70.6)$ & 13 (41.9) & & \\
\hline
\end{tabular}

CC: Cervical cancer; CIN3: cervical intraepithelial neoplasia grade 3; M-CSF: macrophage colony-stimulating factor; MMP2: matrix metalloproteinase 2; TIMP1: tissue inhibitor of matrix metalloproteinase 1. Significantly different: aCC $v s$. ectropion: $p<0.05$; bCC $v s$. CIN3: $p<0.05$; ${ }^{c}$ CIN3 vs. ectropion: $p<0.05$. Score: 0 : None; 1 : weak; 2 : moderate; and 3: strong staining.

The expression of M-CSF was higher in epithelial cells than in stromal cells in cervical ectropion $(p<0.01)$ and in CC $(p<0.001)$. Additionally, higher VEGF expression was found in CC epithelial cells and in dysplastic cells (CIN 3) than stromal cells $(p<0.01$; Table IV).

Regarding MMP2, we also observed stronger positive expression in normal squamous epithelial cells in cervical ectropion and stromal cells $(p<0.05)$. The expression of MMP9 was higher in epithelial cells than in stromal cells in cervical ectropion $(p<0.01)$ and in CC $(p<0.001)$ and was also higher in dysplastic cells when compared to corresponding stromal cells $(p<0.001$, Table V).

In the case of studied TIMPs, higher expression in squamous epithelial cells (cervical ectropion), dysplastic cells (CIN3) or in CC cells was found comparing corresponding stromal cells (for TIMP1: $p<0.1, p<0.05$ and $p<0.001$, respectively; for TIMP2: $p<0.001, p<0.001$ and $p<0.001$, respectively; Table VI) (Figure 1).

No significant difference was demonstrated between the expression of the tested proteins and the histological type of CC (data not shown).

Spearman's rank correlation. Our analysis revealed a statistically significantly positive correlation between plasma levels and cervical epithelial cancer cell expression of VEGF ( $\mathrm{R}=0.43 ; p=0.021)$. Moreover, for TIMP1, negative correlation was also observed between plasma levels and stromal cell expression in $\mathrm{CC}(\mathrm{R}=-0.37, p=0.038)$, and positive correlation between plasma levels and stromal cells in CIN3 ( $\mathrm{R}=0.50, p=0.039$ ).

\section{Discussion}

CC remains the fourth most frequent cancer in women in poorly developed countries, with an estimated 265,700 causes of death worldwide annually (33). Many internal and external factors are necessary for the development of cancer. Tumors of non-hematological origin often secrete growth factors e.g. M-CSF and VEGF, and overexpress MMPs to sustain incessant proliferation $(34,35)$. Data report a potential role of all the aforementioned markers in CC progression $(36,37)$. Advanced disease correlates with poorer overall survival. Therefore, new potential serum biomarkers are needed in cancer diagnostics due to their simplicity in routine clinical measurement (38).

In this study, attention was focused on plasma levels and tissue expression of cytokines M-CSF, VEGF, MMP2, MMP9 and their inhibitors TIMP1, TIMP2. Results showed a higher concentration of MMP9 and a lower concentration of TIMP2 in patients with $\mathrm{CC}$ and $\mathrm{CIN} 3$ when compared to the ectropion group. Braicu et al. analyzed plasma levels of VEGFA, TIMP2, MMP2, and MMP9 in patients with primary CC to monitor response to chemoradiotherapy (36). High VEGFA levels in patients with $\mathrm{CC}$ were demonstrated, which decreased after adjuvant treatment. A new diagnostic panel of VEGFA and TIMP2 has been suggested for monitoring patients with CC. Low concentrations of TIMP2 suggest that TIMPs (or physiological production by healthy cells) are ineffective in inhibiting large amounts of MMPs from cancerous cells, resulting in the degradation of ECM. Thus, higher TIMP2 concentration in serum is associated with a 
Table IV. Comparison of immunohistochemical cytokine expression in epithelial (normal, dysplastic and cancerous) and stromal cells (only statistically significant data are shown, Wilcoxon test).

\begin{tabular}{|c|c|c|c|c|c|c|c|c|}
\hline & \multirow[b]{2}{*}{ Group } & \multirow[b]{2}{*}{ Cell type } & \multirow[b]{2}{*}{ Score } & \multicolumn{4}{|c|}{$\begin{array}{l}\text { Stromal cells, } \mathrm{n}(\%) \\
\text { Score }\end{array}$} & \multirow[b]{2}{*}{$p$-Value } \\
\hline & & & & 0 & 1 & 2 & 3 & \\
\hline \multirow[t]{7}{*}{ M-CSF } & Cervical ectropion & Normal squamous epithelial & 0 & $3(30.0)$ & $0(0.0)$ & $0(0.0)$ & $0(0.0)$ & $<0.01$ \\
\hline & & & 1 & $6(60.0)$ & $0(0.0)$ & $0(0.0)$ & $0(0.0)$ & \\
\hline & & & 3 & $1(10.0)$ & $0(0.0)$ & $0(0.0)$ & $0(0.0)$ & \\
\hline & $\mathrm{CC}$ & Cancer epithelial & 1 & $4(33.3)$ & $2(16.6)$ & $3(50.0)$ & $0(0.0)$ & $<0.001$ \\
\hline & & & 2 & $2(16.7)$ & $5(41.7)$ & $1(16.7)$ & $0(0.0)$ & \\
\hline & & & 3 & $6(50.0)$ & $5(41.7)$ & $2(33.3)$ & $1(100.0)$ & \\
\hline & & & & \multicolumn{2}{|c|}{0} & 1 & 2 & \\
\hline \multirow[t]{5}{*}{ VEGF } & CIN3 & Dysplastic & 0 & \multicolumn{2}{|c|}{$1(7.7)$} & $1(25.0)$ & $0(0.0)$ & $<0.01$ \\
\hline & & & 1 & \multicolumn{2}{|c|}{$12(92.3)$} & $3(75.0)$ & $1(100.0)$ & \\
\hline & $\mathrm{CC}$ & Cancer epithelial & 0 & \multicolumn{2}{|c|}{$4(22.2)$} & $1(10.0)$ & $0(0.0)$ & $<0.01$ \\
\hline & & & 1 & \multicolumn{2}{|c|}{$13(72.2)$} & $7(70.0)$ & $3(100.0)$ & \\
\hline & & & 2 & \multicolumn{2}{|c|}{$1(5.6)$} & $2(20.0)$ & $0(0.0)$ & \\
\hline
\end{tabular}

CC: Cervical cancer; CIN3: cervical intraepithelial neoplasia grade 3; M-CSF: macrophage colony-stimulating factor; VEGF: vascular endothelial growth factor. Score: 0: None; 1: weak; 2: moderate; and 3: strong staining.

Table V. Comparison of the immunohistochemical expression of selected metalloproteinases (MMP2 and MMP9) in epithelial (normal, dysplastic and cancerous) and stromal cells (only statistical significance).

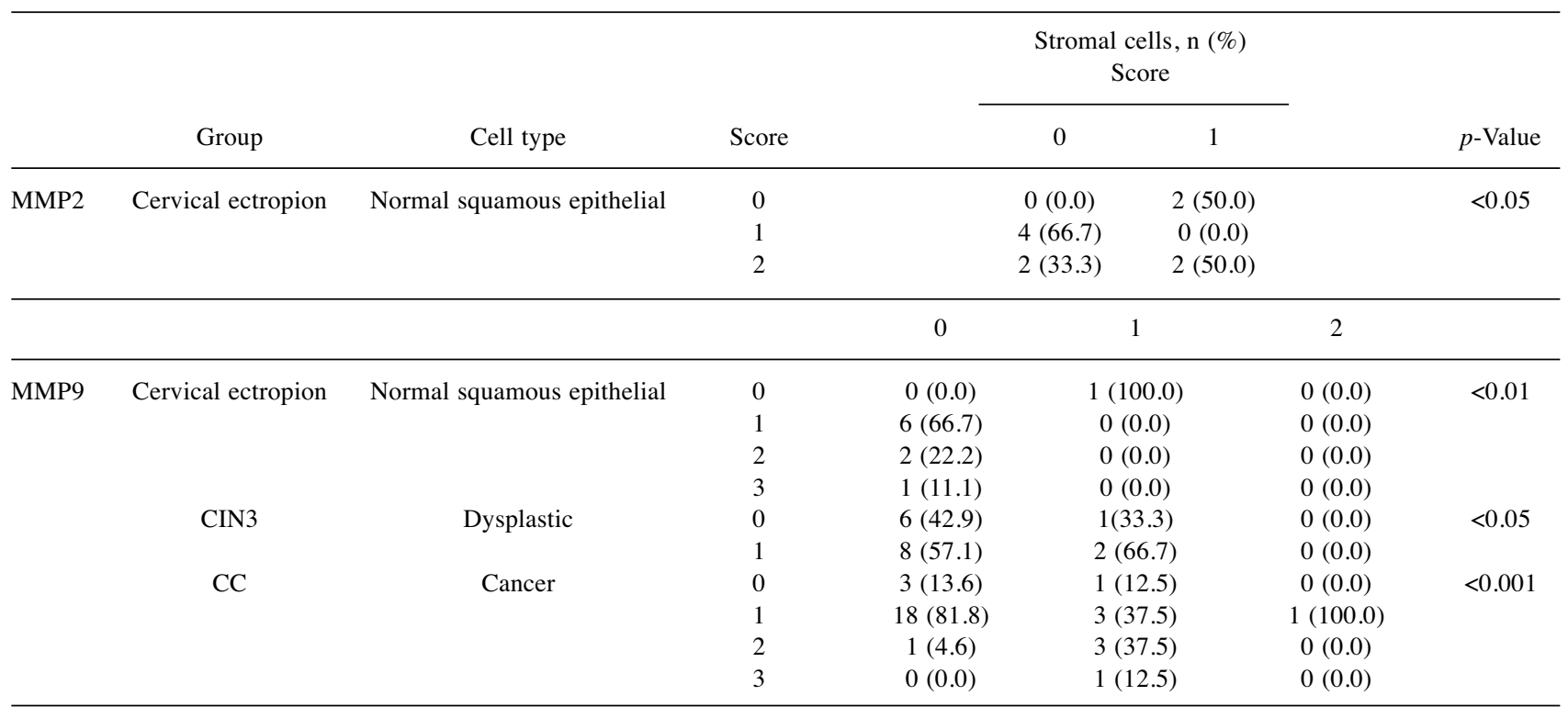

CC: Cervical cancer; CIN3: cervical intraepithelial neoplasia grade 3. Score: 0: None; 1: weak; 2: moderate; and 3: strong staining.

better clinical outcome. Braicu et al. showed that a TIMP2 concentration lower than $90 \mathrm{ng} / \mathrm{ml}$ was significantly associated with poorer overall and progression-free survival (39). In the current study, the usefulness of TIMP2 and MMP9 in the differential diagnosis of ectropion, CIN3, and $\mathrm{CC}$ has been indicated. It has been demonstrated that MMP9 concentration increase with the clinical stage of the tumor (40).

Cancer cells constitute a source of various growth factors, which are excreted to the stroma. Under physiological conditions, stromal cells create a barrier against epithelial cell 
Table VI. Comparison of the immunohistochemical expression of tissue inhibitors of metalloproteinases (TIMPs) in epithelial (normal, dysplastic and cancerous) and stromal cells (only statistical significance).

\begin{tabular}{|c|c|c|c|c|c|c|c|c|}
\hline & \multirow[b]{2}{*}{ Group } & \multirow[b]{2}{*}{ Cell type } & \multirow[b]{2}{*}{ Score } & \multicolumn{4}{|c|}{$\begin{array}{c}\text { Stromal cells, } \mathrm{n}(\%) \\
\text { Score }\end{array}$} & \multirow[b]{2}{*}{$p$-Value } \\
\hline & & & & 0 & 1 & 2 & 3 & \\
\hline \multirow[t]{9}{*}{ TIMP1 } & Cervical ectropion & Normal squamous epithelial & 0 & $1(33.33)$ & $0(0.0)$ & $0(0.0)$ & $0(0.0)$ & $<0.01$ \\
\hline & & & 2 & $1(33.33)$ & $1(14.3)$ & $0(0.0)$ & $0(0.0)$ & \\
\hline & & & 3 & $1(33.33)$ & $6(85.7)$ & $0(0.0)$ & $0(0.0)$ & \\
\hline & CIN3 & Dysplastic & 2 & $3(50.0)$ & $2(20.0)$ & $0(0.0)$ & $0(0.0)$ & $<0.001$ \\
\hline & & & 3 & $3(50.0)$ & $8(80.0)$ & $1(100.0)$ & $0(0.0)$ & \\
\hline & $\mathrm{CC}$ & Cancer & 1 & $6(75.0)$ & $0(0.0)$ & $0(0.0)$ & $0(0.0)$ & $<0.001$ \\
\hline & & & 2 & $1(12.5)$ & $11(52.4)$ & $0(0.0)$ & $0(0.0)$ & \\
\hline & & & 3 & $1(12.5)$ & $10(47.6)$ & $1(100.0)$ & $1(100.0)$ & \\
\hline & & & & \multicolumn{2}{|c|}{0} & \multicolumn{2}{|c|}{1} & \\
\hline \multirow[t]{11}{*}{ TIMP2 } & Cervical ectropion & Normal squamous epithelial & 0 & \multicolumn{2}{|c|}{$1(20.0)$} & \multicolumn{2}{|c|}{$0(0.0)$} & $<0.05$ \\
\hline & & & 1 & \multicolumn{2}{|c|}{$2(40.0)$} & \multicolumn{2}{|c|}{$3(75.0)$} & \\
\hline & & & 2 & \multicolumn{2}{|c|}{$2(40.0)$} & \multicolumn{2}{|c|}{$1(12.5)$} & \\
\hline & \multirow{4}{*}{ CIN3 } & & 3 & \multicolumn{2}{|c|}{$0(0.0)$} & \multicolumn{2}{|c|}{$1(12.5)$} & \\
\hline & & \multirow[t]{3}{*}{ Dysplastic } & 1 & \multicolumn{2}{|c|}{$9(81.8)$} & \multicolumn{2}{|c|}{$1(16.7)$} & $<0.001$ \\
\hline & & & 2 & \multicolumn{2}{|c|}{$2(18.2)$} & \multicolumn{2}{|c|}{$2(33.3)$} & \\
\hline & & & 3 & \multicolumn{2}{|c|}{$0(0.0)$} & \multicolumn{2}{|c|}{$3(50.0)$} & \\
\hline & \multirow[t]{4}{*}{$\mathrm{CC}$} & \multirow[t]{4}{*}{ Cancer } & 0 & \multicolumn{2}{|c|}{$3(10.0)$} & \multicolumn{2}{|c|}{$2(18.1)$} & $<0.001$ \\
\hline & & & 1 & \multicolumn{2}{|c|}{$14(46.7)$} & \multicolumn{2}{|c|}{$4(36.4)$} & \\
\hline & & & 2 & \multicolumn{2}{|c|}{$12(40.0)$} & \multicolumn{2}{|c|}{$4(36.4)$} & \\
\hline & & & 3 & \multicolumn{2}{|c|}{$1(3.3)$} & & & \\
\hline
\end{tabular}

CC: Cervical cancer; CIN3: cervical intraepithelial neoplasia grade 3. Score: 0: None; 1: weak; 2: moderate; and 3: strong staining.

transformation. However, the stromal compartment undergoes extensive remodeling in response to progressive changes in the epithelium. The rearrangement of the tumor environment has an important role in several processes related to cancer progression, including recruitment of new stromal cells that secrete factors stimulating cell proliferation and matrix remodeling (40). MMPs regulate tumor development by the remodeling of ECM components. Fernandes et al. showed greater expression of MMP2 in the stromal cells of invasive carcinoma of the cervix than in CIN3 and assumed that stromal cells play a crucial role in tumor progression (41). However, our results are opposed and showed no statistical differences in expression of the studied MMPs between groups. We detected the expression of MMP2 in normal squamous epithelial cells and stromal cells, but we noted no statistical discrepancy between cancerous and stromal MMP2. Interestingly, our results are similar to those of Westin et al. (42). The expression of MMP2 and MMP9 was detected as slight in control samples and increased in patients with $\mathrm{CC}$. The researchers suggested that MMP2 and MMP9 expression were associated with the stage of CC and the age of patients. In our study, we did not notice differences in expression of MMP9 between the CIN3, CC and ectropion groups. We indicated the relationship between the expression of MMP9 in epithelial and stromal cells. Similarly, Li et al. detected that MMP9 expression was increased in CC compared to normal tissue, which was associated with stromal invasion, CC stage and lymph node metastasis (43). Interestingly, results by Westlin et al. showed significantly higher expression of MMP9 in tumor stroma than in cancerous cells (42). In our examinations, stronger positive MMP9 reaction in dysplastic cells was detected compared to stromal cells in CIN3. Moreover, higher MMP9 expression in normal squamous epithelial cells than in stromal cells was observed. Notably, this might be the effect of huge epithelial remodeling whereby proliferative keratinocytes migrated inside the stroma, which leads to an increase in the expression of

Figure 1. Immunohistochemical expression of macrophage-colony stimulating factor (M-CSF; absent in normal epithelium moderate in CIN3 and strong in CC), vascular endothelial growth factor (VEGF; weak in normal epithelial tissue, absent in CIN3, weak in CC), matrix metalloproteinase 2 (MMP2; moderate in normal epithelial tissue, weak in CIN3 and CC), matrix metalloproteinase 9 (MMP9; absent in normal epithelial tissue, weak in CIN3 and CC), tissue inhibitor of matrix metalloproteinase 1 (TIMP1; strong in normal epithelium and CIN3 and absent in CC) and tissue inhibitor of matrix metalloproteinase 2 (TIMP2; absent in normal epithelial tissue and in CIN3 and moderate in CC) observed in cell cytoplasm (magnification $\times 200$ ). 


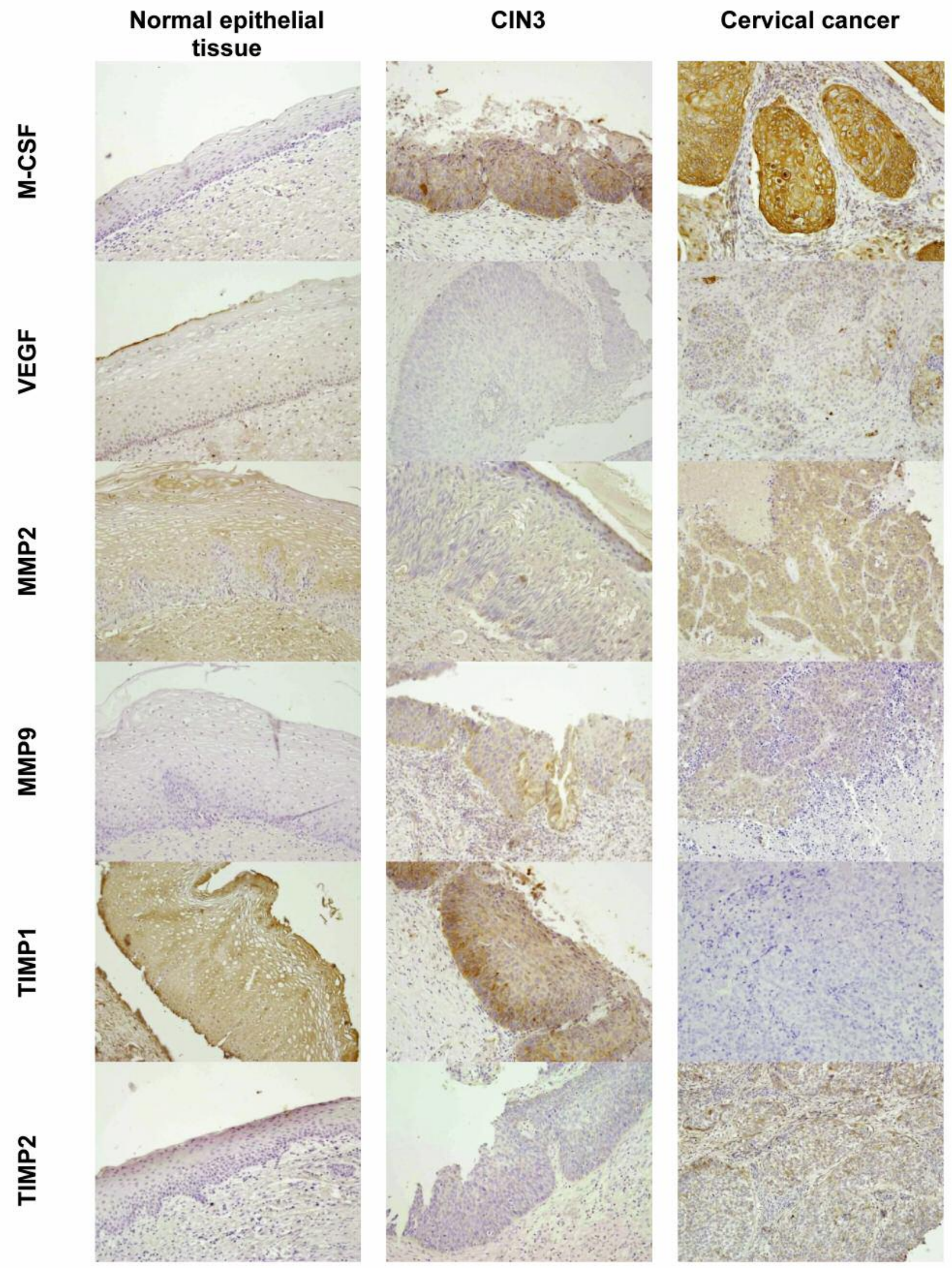


MMPs. Data confirmed that MMP9 expression in CC may be an independent prognostic factor, and might be a potential diagnostic target $(42,43)$.

Zhou et al. observed different expression of TIMP1 and TIMP2 in human squamous cell carcinoma of the uterine cervix (44). They indicated higher positive rate in TIMP1 and TIMP2 expression among CC and CIN in comparison to normal tissue. In our studies, expression of TIMP1 and TIMP2 in all tested groups was detected, but we only noted statistically significant differences in the expression of TIMP1. Similarly, Westin et al. found the percentage of cells expressing TIMP1 was statistically higher in cancerous cells compared to cells in the CIN3 group (42). They also demonstrated no statistical differences in the expression of TIMP2 between patients with CIN3 and those with CC. High expression of TIMPs plays an important role in the remodeling of the epithelium. Overexpression of TIMPs was shown to reduce MMP activity, which directly suppressed remodeling of the tumor environment. TIMPs inhibit vascular smooth muscle and endothelial cell migration, but also possess growth factor activity (45).

VEGF is potent angiogenic agent and its increased production induces blood vessel growth (30). It might be considered a useful diagnostic biomarker in $\mathrm{CC}$. The expression level of VEGF increases with the decline of oxygen concentration in various types of malignant cells (46, 47). Moreover, VEGF can increase vascular permeability, promote cell migration and inhibit apoptosis (48). Zhang et al. demonstrated that the positive expression of VEGF was significantly higher in $\mathrm{CC}$ than in normal cervical tissue. In their study, VEGF mRNA expression was also detected. High expression of VEGF was associated with an increased metastatic potential of tumor cells and a poor survival rate (49). Belfort-Mattos et al. demonstrated a positive correlation between the expression of VEGF and CIN grade, which suggests a tendency for strong VEGF expression among patients with high-grade lesions (50). The results presented from our study showed no difference in the expression of VEGF among those with cervical ectropion, CIN3 and CC, however the VEGF tissue expression and plasma levels were correlated. Our data showed higher expression of the protein in cancerous and dysplastic cells than in stromal cells, which may suggest that the presence of VEGF expression is strongly associated with high-grade intraepithelial lesions.

Different macrophage populations co-exist within single tissues. Tumor-associated macrophages often occur in solid tumors, which affects their development. Tumor cells produce $\mathrm{M}-\mathrm{CSF}$ as a tumor-associated macrophage regulatory factor for differentiation and proliferation (51). It is hypothesized that the expression of M-CSF and its receptor are involved in the progression of female cancer (52). In murine models of cervical carcinogenesis, the pharmacological inhibition of $\mathrm{M}$ CSF receptor also inhibited the tumor growth (53). Moreover, silencing M-CSF gene expression using regulatory siRNA inhibited the process of angiogenesis (54). Our data revealed a higher expression of this protein in tumor cells in comparison with normal squamous epithelial cells. Kirma et al. similarly showed elevated expression of M-CSF in tumor cells in comparison to normal epithelium (52).

In summary, to our knowledge, this is the first comparative analysis of tissue expression and serum concentration of selected parameters in epithelial lesions of the cervix and stromal compartment. Depending on the type of lesion, different concentrations and tissue expression of these proteins were observed. Statistical differences in the expression of M-CSF, MMP2, and TIMP1 among normal squamous epithelial, dysplastic and cancerous cells may indicate a potential role of these proteins in CC diagnosis. Moreover, the statistical differences in serum concentrations of MMP9 and TIMP2 and lack of such differences in tissue expression suggest that these proteins play a questionable role in progression of epithelial lesions. The lack of correlation between the plasma level and tissue expression of M-CSF, MMPs and TIMPs indicates that these proteins in serum are derived from blood cells, and therefore do not reflect the severity of the remodeling in the tumor itself but a peripheral response, and should not be evaluated as a marker of an ongoing process in the cervix. Our findings confirm that the plasma level of VEGF is correlated with tissue expression, nevertheless, its usefulness in the diagnosis of $\mathrm{CC}$ is uncertain. However, it can be hypothesized that a diagnostic panel with VEGF may be sufficient for the detection of CC. To confirm our findings, further investigation and enlargement of the study group to predict if these parameters can be used as potential diagnostic markers in $\mathrm{CC}$ is required.

\section{Conflicts of Interest}

There are no conflicts of interest to disclose.

\section{Authors' Contributions}

IS, MZ-K and SL contributed to study design. KG-U and AP performed the immunohistochemical analysis. IS, BP and EL performed plasma measurements. IS, BP and EL performed statistical analysis and edited the article. IS, BP and SL drafted the article. MZ-K SL, KG-U and AP collected the samples. All Authors contributed to interpretation of the results, provided critical input into all redrafts of the article and approved the final version.

\section{References}

1 McGraw SL and Ferrante JM: Update on prevention and screening of cervical cancer. World J Clin Oncol 5: 744-752, 2014. PMID: 25302174. DOI: 10.5306/wjco.v5.i4.744

2 Aggarwal P: Cervical cancer: Can it be prevented? World J Clin Oncol 5(4): 775-780, 2014. PMID: 25302177. DOI: 10.5306/ wjco.v5.i4.775 
3 Dasari S, Wudayagiri $\mathrm{R}$ and Valluru L: Cervical cancer: Biomarkers for diagnosis and treatment. Clin Chim Acta 445: 7 11, 2015. PMID: 25773118. DOI: 10.1016/j.cca.2015.03.005

4 Perkins GL, Slater ED, Sanders GK and Prichard JG: Serum tumor markers. Am Fam Physician 68: 1075-1082, 2014. PMID: 14524394.

5 Chakraborti S, Mandal M, Das S, Mandal A and Chakraborti T: Regulation of matrix metalloproteinases. An overview. Mol Cell Biochem 253(1-2): 269-285, 2003. PMID: 14619979. DOI: 10.1023/A: 1026028303196

6 Bauvois B: New facets of matrix metalloproteinases MMP-2 and MMP-9 as cell surface transducers: Outside-in signaling and relationship to tumor progression. Biochim Biophys Acta Rey Cancer 1825(1): 29-36, 2012. PMID: 22020293. DOI: 10.1016/ j.bbcan.2011.10.001

7 Deryugina EI and Quigley JP: Pleiotropic roles of matrix metalloproteinases in tumor angiogenesis: Contrasting, overlapping and compensatory functions. Biochim Biophys Acta Mol Cell Res 1803(1): 103-120, 2010. PMID: 19800930. DOI: 10.1016/j.bbamcr.2009.09.017

8 Bergers G, Brekken R, McMahon G, Vu TH, Itoh T, Tamaki K, Tanzawa K, Thorpe P, Itohara S, Werb Z and Hanahan D: Matrix metalloproteinase- 9 triggers the angiogenic switch during carcinogenesis. Nat Cell Biol 2: 737-744, 2000. PMID: 11025665. DOI: $10.1038 / 35036374$

9 Djonov V, Cresto N, Aebersold DM, Burri PH, Altermatt HJ, Hristic M, Berclaz G, Ziemiecki A and Andres AC: Tumor cellspecific expression of MMP-2 correlates with tumor vascularisation in breast cancer. Int J Oncol 21(1): 25-30, 2002. PMID: 19800930. DOI: 10.3892/ijo.21.1.25

10 Kenny HA and Lengyel E: MMP-2 functions as an early response protein in ovarian cancer metastasis. Cell Cycle 8(5): 683-688, 2009. PMID: 19221481. DOI: 10.4161/cc.8.5.7703

11 Arpino V, Brock M and Gill SE: The role of TIMPs in regulation of extracellular matrix proteolysis. Matrix Biol 44-46: 247-254, 2015. PMID: 25805621. DOI: 10.1016/j.matbio.2015.03.005

12 Brew $\mathrm{K}$ and Nagase $\mathrm{H}$ : The tissue inhibitors of metalloproteinases (TIMPs): An ancient family with structural and functional diversity. Biochim Biophys Acta Mol Cell Res 1803(1): 55-71, 2010. PMID: 20080133. DOI: 10.1016/ j.bbamcr.2010.01.003

13 Remillard TC, Bratslavsky G, Jensen-Taubman S, StetlerStevenson WG and Bourboulia D: Molecular mechanisms of tissue inhibitor of metalloproteinase 2 in the tumor microenvironment. Mol Cell Ther 2: 17, 2014. PMID: 26056585. DOI: $10.1186 / 2052-8426-2-17$

14 Bourboulia D and Stetler-Stevenson WG: Matrix metalloproteinases (MMPs) and tissue inhibitors of metalloproteinases (TIMPs): Positive and negative regulators in tumor cell adhesion. Semin Cancer Biol 20(3): 161-168, 2010. PMID: 20470890. DOI: 10.1016/j.semcancer.2010.05.002

15 Westermarck $\mathrm{J}$ and Kähäri VM: Regulation of matrix metalloproteinase expression in tumor invasion. FASEB J 13(8): 781-792, 1999. PMID: 10224222.

16 Egeblad $\mathrm{M}$ and Werb $\mathrm{Z}$ : New functions for the matrix metalloproteinases in cancer progression. Nat Rev Cancer 2(3): 161-174, 2002. PMID: 11990853. DOI: $10.1038 / \mathrm{nrc} 745$

17 Chirco R, Liu XW, Jung KK and Kim HRC: Novel functions of TIMPs in cell signaling. Cancer Metastasis Rev 25(1): 99-113, 2006. PMID: 16680576. DOI: 10.1007/s10555-006-7893-x
18 Lewis CE and Pollard JW: Distinct role of macrophages in different tumor microenvironments. Cancer Res 66(2): 605-612, 2006. PMID: 16423985. DOI: 10.1158/0008-5472.CAN-05-4005

19 Achkova D and Maher J: Role of the colony-stimulating factor (CSF)/CSF-1 receptor axis in cancer. Biochem Soc Trans 44(2): 333-341, 2016. PMID: 27068937. DOI: 10.1042/BST20150245

20 Zajkowska M, Głazewska EK, Bȩdkowska GE, Chorazy P, Szmitkowski M and Ławicki S: Diagnostic power of vascular endothelial growth factor and macrophage colony-stimulating factor in breast cancer patients based on ROC analysis. Mediators Inflamm 2016: 5962946, 2016. PMID: 27445439. DOI: $10.1155 / 2016 / 5962946$

21 Richardsen E, Uglehus RD, Johnsen SH and Busund LT: Macrophage-colony stimulating factor (CSF1) predicts breast cancer progression and mortality. Anticancer Res 35(2): 865874, 2015. PMID: 25667468.

22 Kenichi H, Akihiro H, Takayuki K, Keisuke S, Sachiko W and Noriyuki K: Use of colony-stimulating factor in patients with ovarian cancer receiving paclitaxel and carboplatin in Japan. J Gynecol Oncol 25(2): 124-129, 2014. PMID: 24761216. DOI: 10.3802/jgo.2014.25.2.124

23 Poonawalla IB, Piller LB, Lairson DR, Chan W and Du XL: Use of hematopoietic growth factors and risk of thromboembolic and pulmonary toxicities in elderly patients with advanced ovarian cancer. Women's Heal Issues 26(5): 574-583, 2016. PMID: 27365286. DOI: 10.1016/j.whi.2016.05.007

24 Aharinejad S, Salama M, Paulus P, Zins K, Berger A and Singer CF: Elevated CSF1 serum concentration predicts poor overall survival in women with early breast cancer. Endocr Relat Cancer 20(6): 777783, 2013. PMID: 24016870. DOI: 10.1530/ERC-13-0198

25 Ławicki S, Głazewska EK, Sobolewska M, Bȩdkowska GE and Szmitkowski M: Plasma levels and diagnostic utility of macrophage colony-stimulating factor, matrix metalloproteinase9, and tissue inhibitor of metalloproteinases- 1 as new biomarkers of breast cancer. Ann Lab Med 36(3): 223-229, 2016. PMID: 26915610. DOI: 10.3343/alm.2016.36.3.223

26 Rego SL, Helms RS and Dréau D: Breast tumor cell TACE-shed MCSF promotes pro-angiogenic macrophages through NF- $x \mathrm{~B}$ signaling. Angiogenesis 17(3): 573-585, 2014. PMID: 24197832. DOI: $10.1007 / \mathrm{s} 10456-013-9405-2$

27 Dvorak HF: Vascular permeability factor/vascular endothelial growth factor: A critical cytokine in tumor angiogenesis and a potential target for diagnosis and therapy. J Clin Oncol 20(21): 4368-4380, 2002. PMID: 12409337. DOI: $10.1200 / J C O .2002 .10 .088$

28 Frumovitz M and Sood AK: Vascular endothelial growth factor (VEGF) pathway as a therapeutic target in gynecologic malignancies. Gynecol Oncol 104: 768-778, 2007. PMID: 17306693. DOI: 10.1016/j.ygyno.2006.10.062

29 Abdalla D, Simoens C, Bogers J-P, Murta E and Michelin M: Angiogenesis markers in gynecological tumors and patents for anti- angiogenic approach: review. Recent Pat Anticancer Drug Discov 10(3): 298-307, 2015. PMID: 26381660. DOI: 10.2174/ 1574892810999150827153642

30 Vempati P, Popel AS and Mac Gabhann F: Extracellular regulation of VEGF: Isoforms, proteolysis, and vascular patterning. Cytokine Growth Factor Rev 25: 1-19, 2014. PMID: 24332926. DOI: 10.1016/j.cytogfr.2013.11.002

31 Pecorelli S: Revised FIGO staging for carcinoma of the vulva, cervix, and endometrium. Int J Gynaecol Obstet 105(2): 103104, 2009. PMID: 19367689. DOI: 10.1016/j.ijgo.2009.02.012 
32 Piskor BM, Pryczynicz A, Lubowicka E, Miniewska K, Zinczuk $\mathrm{J}$, Zareba $\mathrm{K}$ and Guzinska-Ustymowicz K: Immunohistochemical expression of Fascin-1 in colorectal cancer in relation to clinical and pathological parameters. Folia Histochem Cytobiol 56(2): 106-112, 2018. PMID: 29888780. DOI: 10.5603/FHC.a2018.0011

33 Torre LA, Islami F, Siegel RL, Ward EM and Jemal A: Global cancer in women: Burden and trends. Cancer Epidemiol Biomarkers Prev 26(4): 444-457, 2017. PMID: 28223433. DOI:10.1158/1055-9965.EPI-16-0858

34 Chockalingam S and Ghosh SS: Macrophage colony-stimulating factor and cancer: a review. Tumor Biol 35(11): 10635-10644, 2014. PMID: 25238879. DOI: 10.1007/s13277-014-2627-0

35 Shuman Moss LA, Jensen-Taubman S and Stetler-Stevenson WG: Matrix metalloproteinases: Changing roles in tumor progression and metastasis. Am J Pathol 181(6): 1895-1899, 2012. PMID: 23063657. DOI: 10.1016/j.ajpath.2012.08.044

36 Braicu EI, Gasimli K, Richter R, Nassir M, Kümmel S, Blohmer JU, Yalcinkaya I, Chekerov R, Ignat I, Ionescu A, Mentze M, Fotopoulou C, Pop C, Lichtenegger W, Sehouli J, Tumor Bank Ovarian Cancer (TOC) and German North Eastern Society for Gynecological Oncology (NOGGO): Role of serum VEGFA, TIMP2, MMP2 and MMP9 in monitoring response to adjuvant radiochemotherapy in patients with primary cervical cancer Results of a companion protocol of the randomized NOGGOAGO phase III clinical trial. Anticancer Res 34(1): 385-391, 2014. PMID: 24403492.

37 Cho MJ, Lee JY, Shin MG, Kim HJ, Choi YJ, Rho SB, Kim BR, Jang IS and Lee SH: TSC-22 inhibits CSF-1R function and induces apoptosis in cervical cancer. Oncotarget 8(58): 9799098003, 2017. PMID: 29228668. DOI: 10.18632/oncotarget.20296

38 Gadducci A, Tana R, Cosio S and Genazzani AR: The serum assay of tumour markers in the prognostic evaluation, treatment monitoring and follow-up of patients with cervical cancer: A review of the literature. Crit Rev Oncol Hematol 66(1): 10-20, 2008. PMID: 17964182. DOI:10.1016/j.critrevonc.2007.09.002

39 Braicu EI, Fotopoulou C, Chekerov R, Richter R, Blohmer J, Kümmel S, Stamatian F, Yalcinkaya I, Mentze $M$, Lichtenegger W and Sehouli J: Role of serum concentration of VEGFR1 and TIMP2 on clinical outcome in primary cervical cancer: Results of a companion protocol of the randomized, NOGGO-AGO phase III adjuvant trial of simultaneous cisplatin-based radiochemotherapy vs. carboplatin and pac. Cytokine 61(3): 755-758, 2013. PMID: 23415672. DOI: $10.1016 /$ j.cyto.2013.01.013

40 Lubowicka E, Gacuta E, Zajkowska M, Głażewska EK, Przylipiak A, Chrostek L, Zbucka-Krętowska M and Ławicki S: The plasma levels and diagnostic utility of matrix metalloproteinase-9 and CA 125 in cervical cancer patients. Pol Merkur Lekarski 43(253): 10-14, 2017. PMID: 28805195.

41 Tlsty TD and Coussens LM: Tumor stroma and regulation of cancer development. Annu Rev Pathol Mech Dis 1: 119-150, 2006. PMID: 18039110. DOI: 10.1146/annurev.pathol. 1.110304 .100224

42 Westin MC and Rabelo-Santos SH: Expression of MMP-2, MMP-9, MMP-14, TIMP-1, TIMP-2 in Intraepithelial and Invasive Cervical Neoplasia. J Cytol Histol S3: 019, 2015. DOI: 10.4172/2157-7099.S3-019

$43 \mathrm{Li} \mathrm{Y,} \mathrm{Wu} \mathrm{T,} \mathrm{Zhang} \mathrm{B,} \mathrm{Yao} \mathrm{Y} \mathrm{and} \mathrm{Yin} \mathrm{G:} \mathrm{Matrix} \mathrm{metallo-}$ proteinase-9 is a prognostic marker for patients with cervical cancer. Med Oncol 29(5): 3394-3399, 2012. PMID: 22752570. DOI: $10.1007 / \mathrm{s} 12032-012-0283$

44 Zhou $\mathrm{C}$ yun, Yao J fen and Chen $\mathrm{X}$ duan: Expression of matrix metalloproteinase-2, 9 and their inhibitor-TIMP 1,2 in human squamous cell carcinoma of uterine cervix. Ai Zheng 21(7): 735739, 2002. PMID: 12479097.

45 Jiang Y, Goldberg ID and Shi YE: Complex roles of tissue inhibitors of metalloproteinases in cancer. Oncogene 21(14): 22452252, 2002. PMID: 11948407. DOI:10.1038/sj.onc.1205291

46 Goncharuk IV, Vorobjova LI, Lukyanova NY and Chekhun VF: Vascular endothelial growth factor exression in uterine cervical cancer: Correlation with clinicopathologic characteristics and survival. Exp Oncol 31(3): 179-181, 2009. PMID: 19783962.

47 Srivastava S, Gupta A, Agarwal GG, Natu SM, Uma S, Goel MM and Srivastava AN: Correlation of serum vascular endothelial growth factor with clinicopathological parameters in cervical cancer. Biosci Trends 3(4): 144-150, 2009. PMID: 20103839.

48 Zhang J, Liu J, Zhu C, He J, Chen J, Liang Y, Yang F, Wu X and Ma X: Prognostic role of vascular endothelial growth factor in cervical cancer: A meta-analysis. Oncotarget 8(15): 24797-24803, 2017. PMID: 28177889. DOI: $10.18632 /$ oncotarget.15044

49 Zhang L, Chen Q, Hu J, Chen Y, Liu C and Xu C: Expression of HIF-2 $\alpha$ and VEGF in cervical squamous cell carcinoma and its clinical significance. Biomed Res Int 2016: 5631935, 2016. PMID: 27413748. DOI: 10.1155/2016/5631935

50 Belfort-Mattos PN, Focchi GRDA, Ribalta JCL, Megale De Lima T, Nogueira Carvalho CR, Kesselring Tso F and De Góis Speck NM: Immunohistochemical expression of VEGF and podoplanin in uterine cervical squamous intraepithelial lesions. Dis Markers 2016: 8293196, 2016. PMID: 27313335. DOI: $10.1155 / 2016 / 8293196$

51 Dwyer AR, Greenland EL and Pixley FJ: Promotion of tumor invasion by tumor-associated macrophages: The role of CSF-1activated phosphatidylinositol 3 kinase and Src family kinase motility signaling. Cancers 9(6): pii: E68, 2017. PMID: 28629162. DOI:10.3390/cancers 9060068

52 Kirma N, Hommes LS, Liu YG, Nair HB, Valente PT, Kumar S, Flowers LC and Tekmal RR: Elevated expression of the oncogene c-FMS and its ligand, the macrophage colonystimulating factor-1, in cervical cancer and the role of transforming growth factor- $\beta 1$ in inducing c-FMS expression. Cancer Res 67(5): 1918-1926, 2007. PMID: 17332318. DOI: 10.1158/0008-5472.CAN-06-1991

53 Strachan DC, Ruffell B, Oei Y, Bissell MJ, Coussens LM, Pryer $\mathrm{N}$ and Daniel D: CSF1R inhibition delays cervical and mammary tumor growth in murine models by attenuating the turnover of tumor-associated macrophages and enhancing infiltration by CD8+ T-cells. Oncoimmunology 2(12): e26968, 2013. PMID: 24498562. DOI: 10.4161/onci.26968

54 Coffelt SB, Hughes R and Lewis CE: Tumor-associated macrophages: Effectors of angiogenesis and tumor progression. Biochim Biophys Acta Rev Cancer 1796(1): 11-18, 2009. PMID: 19269310. DOI: 10.1016/j.bbcan.2009.02.004

Received September 15, 2019

Revised October 10, 2019

Accepted October 14, 2019 